\title{
Forming Legal Definitions of Modern Information Technologies under Economic Digitalization
}

\author{
K. K. $\operatorname{Taran}^{1} *$ \\ *Corresponding author: taran.kira@yndex.ru \\ ${ }^{1}$ Moscow State Institute of International Relations (University) of the Ministry of Foreign Affairs, Moscow, Russia
}

\begin{abstract}
During the intensive development of information technologies (IT), the need for their regulation gradually arises. For forming basic regulation of IT-sphere a basis is needed, which determines the subject of regulation. It's a complicated task, but its solution will help to determine legal relations stemming from ITusage. The existing technical definitions are accurate, since they are technical in nature. In some situations there are difficulties in their legal application, it complicates the legal analysis of a specific situation. The legal definition of a particular technology will assist legal professionals and theorists, as it will clarify the essence of relations, help to avoid misconception, support Internet law developing. This study discusses a short list of technologies used in practice in legal, medical and other fields. The author provides an overview of legal definitions at various levels: international, regional and national. The author examines the formation of definitions in Russia and the USA. A comparative analysis of terminology allows us to highlight the laws and features inherent in these countries. The author discusses the definitions of well-known, basic concepts such as the Internet, the user and the definition of technology that is currently widely used - a cloud storage of information.
\end{abstract}

Keywords: legal definition, information technology, Internet law, understanding, legal relations on the Internet

\section{Introduction}

In the modern world, technology is developing very rapidly. The number of technology users among such entities as individuals, legal entities, government bodies is growing, and with this the use of IT is spreading in various fields: education, medicine, law, the media (film industry, news services, etc.), trade etc. When technologies begin to be applied as actively and even rather globally, as the Internet itself, there is a need not only to regulate new legal relations, but also to create a conceptual framework that would be useful and introduce clarity to lawyers, law enforcers and the subjects that use technology. In this study, the author minimizes the use of technical definitions. The study discusses the most used, according to the author, technology.

\section{Problem Statement}

The problem of this study is how to formulate the most optimal legal definition of technology, how to be guided when creating this definition, whether to use the experience of foreign countries, whether it is necessary to specify the existing definitions (for example, in the situation of a consumer and a user), etc. The definition should be formulated in such a way that it is the basis for regulation, so that it is understandable for people working in the legal sphere. Therefore this problem is of great importance for the development of legal thought. Moreover, it is important how the definition will be voluminous in content. The less it will be voluminous, the more freedom will be given to the development of legal regulation.

\section{Research Questions}

The author considers the following issues:How were different definitions formed? What conditions influenced them? What are differences in definitions of specific technology by different actors?

\section{Purpose of the Study}

The author sets the task of studying legislation at various levels (international and national, using the example of Russia and foreign countries), judicial practice and doctrine. Based on the material studied, the author presents the most optimal definitions and suggests a possible version of a term.

The purpose of this study is to compare the formation of definitions in Russia, the USA and the EU, to highlight their features and patterns. The purpose of this study is important both for the theory of law and for law enforcement. It is not easy at all to formulate the exact definition after the technology has appeared. The technology needs time to "take root" in society, and to become widespread in practice. The formation of the conceptual definition and its development will create the basis for new definitions of new technologies. 


\section{Research Methods}

When conducting the study, the author used the following general scientific and special methods. The general scientific methods are: analysis - the study of key components of the definition of a particular technology; inductive and deductive methods; modeling methods, etc. Special methods include: comparative legal methods for comparing approaches to formulating definitions in Russia, the USA, and the EU; logical and legal methods, methods of systematic interpretation of legal norms; synergistic method; systematization; and others. It should be noted that the topic of formulating legal definitions affects not only jurisprudence, but also other sciences, such as sociology and cultural studies.

\section{Results}

The author considered the most widely used terms, which, on the one hand, are known to everyone, and on the other hand, not everyone can explain what they represent from a legal point of view. The Internet. The term Internet is very common and has become very firmly established, but there is no definition of the Internet. In international documents, for example, in the UN documents in report A / HRC / 17/27 of May 16, 2011, which recognizes the human right to access the Internet, the Internet is considered as a means of communication, but the definition of the Internet is missing. We can observe a similar situation in Resolution A / RES / 70/125, adopted by the General Assembly on December 16, 2015, which refers to the management of the Internet, its development and dissemination, but its definition is not given. Most likely, this is due to the fact that before giving a definition of this technology, the UN enables states to formulate their own definition and, on the basis of these definitions, they will draw up an optimal unified, legal definition of the term Internet that takes into account all the features.

The US law represents the definition of the Internet. For example, in U.S. Code 47 Section 230 of the Decency Act in the Media (Eng. Communications Decency Act 47 U.S.C. Section 230), the Internet is seen as a service that provides access to educational and information resources and it is implemented with minimal government regulation.

The Regulation 2015/2120 of the European Parliament and of the Council of the European Union of November, 25, 2015 on the establishment of measures regarding open Internet access and the amendment of Directive 2002/22 / EC on universal services and user rights in relation to electronic communications networks and services and the Regulation (EU ) 531/2012 on the roaming of public mobile networks within the Union also do not contain a definition of the Internet; the Internet is more likely defined as a means of communication to which end-user access should be provided.

In Russia, there are some definitions of the Internet. In the Federal Act of July 27, $2006 \mathrm{~N}$ 149-FZ "On Information Technologies and Protection of Information", the Internet is defined as an information and telecommunication network.

Taking into account how the Internet is widespread now and taking into account how many different services are provided through it, you can define it as a social phenomenon characterized by the universal global availability of bidirectional digital communication services, both between people and between their belongings. The Internet is by far the first and only global public service.

The second term that also needs to be considered is the user. As mentioned in earlier documents, the human right to access the Internet is recognized at the international level. The international community calls for the spread of the Internet as a means of expressing freedom of a person and citizen. But still there is the question - who the user is. Often there are terms Internet user, end user, service user, user agreement. Most international documents do not qualify users. Moreover, the term user has not been fixed in the legislation of the Russian Federation and many foreign countries yet. There are difficulties associated with who falls into the category of user, only individuals or legal and state structures will also be users. The answer is rather positive, since both legal entities and government agencies use information technology.

On the other hand, if we talk about users who are individuals and consumers, then what the ratio between the user and the consumer is. According to the Law of the Russian Federation of February 7, 1992 No. 2300-I "On Protection of Consumer Rights", a consumer is a citizen who has the intention to order or purchase, or who orders, purchases or uses goods (works, services) exclusively for personal, family, household and other needs not related to business activities. That is, the user will be considered as a consumer when he is exclusively an individual; legal relations on the use of Internet technologies will be governed by a service agreement, the use of which should not be related to business. It seems that the concept of the consumer will intersect with the concept of the user in the context when the user acts as the consumer. In this regard, numerous questions will arise, what rights the user has, how the protection of consumer rights and the protection of user rights will relate, etc.

Gradually, documents appear that develop the regulation of user rights in general. For example, Recommendation of Ministerial Committee of Council of Europe CM / REC (2014) 6 for States-members about Guidance of Human Rights for Internet Users states that human rights that are universal and indivisible, as well as related standards, take precedence over general provisions and conditions that are imposed on Internet users by any private sector entities. The document recommends the provision of Internet services without discrimination, at a reasonable price, safely, reliably and without interruption. At the same time, users can receive assistance in protecting their rights and use legal remedies. The document is aimed at developing regulation of user rights in both online and offline space.

In the European Union, the regulation of user rights is addressed in Regulation of the European Parliament and the Council of the European Union 2015/2120 of November 25, 2015 on the establishment of measures regarding open 
Internet access and the amendment of Directive 2002/22 / EC on universal services and user rights with respect to networks electronic communications and services and Regulation (EU) 531/2012 on roaming of public mobile networks within the Union. These Regulations establish general rules to ensure an equal and non-discriminatory approach to traffic when providing services for the Internet access and the rights of end users associated with it. The end user refers to the actual user of the service. The Regulations contain general provisions aimed at freedom of access and freedom to use services on the Internet, to disseminate information, the right to defense, including judicial protection. The documents refer to monitoring for the quality of provided services by authorized state bodies. Moreover, as part of the monitoring and enforcement functions, national regulatory authorities and other competent authorities should intervene in contractual and commercial practices if they undermine the nature of the rights of end users.

It is interesting that in spite of the fact that the development of user rights is very active now, opinions are expressed that the user has very few opportunities to protect his rights [15].

Based on the foregoing, it is possible for a user to determine the subject of law who uses the Internet or services provided on the Internet, concluding relevant agreements. Most likely, in the future the states will not only specify the existing acts taking into account such a subject as the user, but will also adopt special acts in which the rights and obligations of the user will be determined.

The above concepts of the Internet and the user are basic for regulation and for the formation of Internet law. Due to the increasing number of technologies and their complication, basic concepts are intertwined with more complex ones, as new applied technologies appear, for example, such as cloud storage. Formation of the legal definition of such a service should be based on basic concepts and should include more complex legal definitions (for example, understanding the user agreement when using cloud storage is based on the legal understanding of the term user).

Cloud storage of information is a server on which user information is stored, and to which the user can access anywhere in the world. The Russian legislation and the legislation of most foreign countries have not developed a legal definition of cloud storage. Cloud storage is an integral part of the cloud service, which includes a wide range of functions, including information storage (the cloud service - came from cloud computing), which includes the storage service).

One of the most relevant definitions of cloud computing was developed by the National Institute of Standards and Technologies (NIST): cloud computing is a model of providing a convenient network access in the "on demand" mode to a collectively used set of configurable computing resources (for example, networks, servers, data storages, etc.) that can be quickly activated and released with minimal interaction with the service provider and minimal own control management efforts (Mell P., 2019). However, this definition is not fixed in the legislation, but it is used in the scientific literature of the USA and other states. This definition can be called generally accepted, but it does not reflect the legal aspects of this technology, as it was given by the technological organization and was not originally planned as legal.

Recently, a definition of cloud computing has been developed in Russia. Cloud computing is an information technology model for providing ubiquitous and convenient access via the Internet to a common set of configurable computing resources (cloud), data storage devices, applications and services that can be quickly provided and freed from the load with minimal operating costs or practically without the participation of the provider (Decree of the President of the RF "On Information Society Development Strategy in the Russian Federation for 2017-2030" of 09.05.2017 N 203). This definition is new, not enshrined in law yet. But this is a significant step in the development of legal regulation of the cloud information storage technology.

The formation of the definition of cloud storage can be traced in judicial practice. The decision of the Moscow City Court of January 21, 2019 in case No. 3-0011 / 2019 states that the Cloud Mail.Ru service is cloud storage that allows registered users (individuals) to download and store files in their personal cloud storage for personal use, access such files in the "cloud" at any time when connected to the Internet, and also provide access to such files to third parties by linking and providing such a link to a third party.

In the ruling of the Thirteenth Arbitration Court of Appeal of April 2, 2019 N 13AP-3256/19, cloud storage of information was defined as a virtual data room (cloud storage), which will be downloaded electronically. And the data for entering cloud storage was designated as login details.

Interestingly, courts do not use cloud storage classifications that match their functionality. For example, in the decision of the Eleventh Arbitration Court of Appeal of February 8, 2017 N 11 AP-18802/16, public cloud storages are called cloud Internet storages, in the definition of the Moscow City Court of July 20, 2017 N 4g-7032/17 it was called external "cloud" file storage. The decisions of the courts of the Russian Federation often contain formulations of personal cloud storage. The writing of cloud storages is also unsteady. Sometimes the word cloud is used in quotation marks when writing, although spelling without quotes is more common.

The name cloud service (English) is also ambiguous. Since the use of the term service is from English, the service already implies the use of a service contract design. But in many law and order, the agreement on the use of cloud storage of information has a different legal nature (discussed later in the work). In this regard, many authors do not use translation, but use the term cloud service, which is not exact, but at the same time it is not misleading about the nature of the contract.

Cloud storage can be defined as a cross-border Internet service that provides access (including remote) to the server on which user information is stored. 


\section{Conclusion}

This study examined important definitions of information technology, but not all of them, since there are many more technologies now. It can be concluded that such general definitions or their absence was a thoughtful step. Taking into account the practice of applying technology and its impact on social relations, we can draw up the most accurate legal definition of both technologies and legal relations. Most likely, definitions given by lawyers in the scientific literature and definitions that are used in judicial practice will serve as the basis for the formation of the conceptual definition in legislative acts.

\section{References}

1. Act of the RF of 7.02.1992 № 2300-I “About Protection Consumers’ Rights”. URL: http://base.garant.ru/10106035/. Accessed: 22.09.2019. (2019).

2. Decision of the Moscow City Court of 21.01.2019 in case N 3-0011/2019. URL: https://www.mosgorsud.ru/mgs/services/cases/first-civil/details/996abf18-f457-4f92-bad4-53193dab23ef. Accessed: 22.09.2019. (2019).

3. Decree of the President of the RF "About Information Society Development Strategy in the Russian Federation for 2017-2030” of 09.05.2017 N 203. URL: https://base.garant.ru/71670570/. Accessed: 22.09.2019. (2019).

4. Federal Act of 27.07.2006 г. N 149-FZ "On Information, Information Technologies and Protection of Information". URL:

http://ivo.garant.ru/\#/document/12148555/paragraph/1844/doclist/0/selflink/0/highlight/\%D0\%98\%D0\%BD\%D1\% 82\%D0\%B5\%D1\%80\%D0\%BD\%D0\%B5\%D1\%82:0. Accessed: 22.09.2019. (2019).

5. I.D. Kuzmina, \& I.S. Bogdanova, Some problems of digital environment influence on the content of civil law object and subject categories. Journal of Siberian Federal University "Humanities \& Social Sciences”, 3(12), 393-409 (2019)

6. P. Mell, \& T. Grance, The NIST definition of cloud computing: Recommendations of the National Institute of

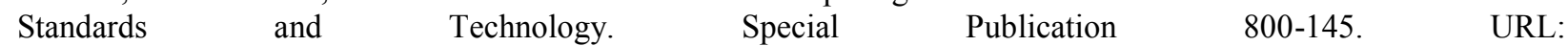
http://nvlpubs.nist.gov/nistpubs/Legacy/SP/nistspecialpublication800-145.pdf. Accessed: 22.09.2019. (2019).

7. Recommendation of Ministerial Committee of Council of Europe CM/REC (2014)6 for States-members about Guidance of human rights for Internet users (adopted by Ministerial Committee of Council of Europe on 16.04.2014 on $1197^{\text {th }}$ meeting of Deputy-Ministers). URL: https://www.refworld.org.ru/pdfid/55cb537c4.pdf. Accessed: 22.09.2019. (2019).

8. Regulation (EU) 2015/2120 of the European Parliament and of the Council of November 25, 2015. URL: https://eurlex.europa.eu/legal-content/EN/TXT/PDF/?uri=CELEX:32015R2120\&from=EN. Accessed: 20.09.2019. (2019).

9. Report of the Special Rapporteur on the Promotion and Protection of the Right to Freedom of Opinion and Expression, Frank La Rue. A/HRC/17/27. URL: https://www2.ohchr.org/english/bodies/hrcouncil/docs/17session/A.HRC.17.27_en.pdf. Accessed: 20.09.2019. (2019).

10. Resolution adopted by the General Assembly on December 16, 2015 . A/RES/70/125. URL: https://undocs.org/en/A/RES/70/125. Accessed: 20.09.2019. (2019).

11. The decision of the Eleventh Arbitration Court of Appeal of 8.02.2017 N 11AP-18802/16. URL: http://base.garant.ru/61761743/. Accessed: 22.09.2019. (2019).

12. The determination of the Moscow City Court on 20.07.2017 N 4g-7032/17. URL: http://ivo.garant.ru/\#/basesearch/\%D0\%9E\%D0\%BF\%D1\%80\%D0\%B5\%D0\%B4\%D0\%B5\%D0\%BB\%D0\%B5\% D0\%BD $\%$ D0\%B8\%D0\%B5\%20\%D0\%9C\%D0\%BE\%D1\%81\%D0\%BA\%D0\%BE\%D0\%B2\%D1\%81\%D0\%BA $\% \mathrm{D} 0 \% \mathrm{BE} \% \mathrm{D} 0 \% \mathrm{~B} 3 \% \mathrm{D} 0 \% \mathrm{BE} \% 20 \% \mathrm{D} 0 \% \mathrm{~B} 3 \% \mathrm{D} 0 \% \mathrm{BE} \% \mathrm{D} 1 \% 80 \% \mathrm{D} 0 \% \mathrm{BE} \% \mathrm{D} 0 \% \mathrm{~B} 4 \% \mathrm{D} 1 \% 81 \% \mathrm{D} 0 \% \mathrm{BA} \% \mathrm{D} 0 \% \mathrm{~B}$ E\%D0\%B3\%D0\%BE\%20\%D1\%81\%D1\%83\%D0\%B4\%D0\%B0\%20\%D0\%BE\%D1\%82\%2020\%20\%D0\%B8\%D $1 \% 8 \mathrm{E} \% \mathrm{D} 0 \% \mathrm{BB} \% \mathrm{D} 1 \% 8 \mathrm{~F} \% 202017 \% 20 \% \mathrm{D} 0 \% \mathrm{~B} 3 . \% 20 \mathrm{~N} \% 204 \% \mathrm{D} 0 \% \mathrm{~B} 3-7032 \mid 17: 0$. Accessed: 22.09.2019. (2019).

13. The ruling of the Thirteenth Arbitration Court of Appeal of 2.04. 2019 N 13AP-3256/19. URL: http://ivo.garant.ru/\#/basesearch/\%D0\%9F\%D0\%BE\%D1\%81\%D1\%82\%D0\%B0\%D0\%BD\%D0\%BE\%D0\%B2\% D0\%BB\%D0\%B5\%D0\%BD\%D0\%B8\%D0\%B5\%20\%D0\%A2\%D1\%80\%D0\%B8\%D0\%BD $\%$ D0\%B0\%D0\%B4 $\% \mathrm{D} 1 \% 86 \% \mathrm{D} 0 \% \mathrm{~B} 0 \% \mathrm{D} 1 \% 82 \% \mathrm{D} 0 \% \mathrm{BE} \% \mathrm{D} 0 \% \mathrm{~B} 3 \% \mathrm{D} 0 \% \mathrm{BE} \% 20 \% \mathrm{D} 0 \% \mathrm{~B} 0 \% \mathrm{D} 1 \% 80 \% \mathrm{D} 0 \% \mathrm{~B} 1 \% \mathrm{D} 0 \% \mathrm{~B} 8 \% \mathrm{D} 1 \% 82$ $\% \mathrm{D} 1 \% 80 \% \mathrm{D} 0 \% \mathrm{~B} 0 \% \mathrm{D} 0 \% \mathrm{~B} 6 \% \mathrm{D} 0 \% \mathrm{BD} \% \mathrm{D} 0 \% \mathrm{BE} \% \mathrm{D} 0 \% \mathrm{~B} 3 \% \mathrm{D} 0 \% \mathrm{BE} \% 20 \% \mathrm{D} 0 \% \mathrm{~B} 0 \% \mathrm{D} 0 \% \mathrm{BF} \% \mathrm{D} 0 \% \mathrm{~B} 5 \% \mathrm{D} 0 \% \mathrm{~B}$ B\%D0\%BB\%D1\%8F\%D1\%86\%D0\%B8\%D0\%BE\%D0\%BD\%D0\%BD\%D0\%BE\%D0\%B3\%D0\%BE\%20\%D1\% $81 \% \mathrm{D} 1 \% 83 \% \mathrm{D} 0 \% \mathrm{~B} 4 \% \mathrm{D} 0 \% \mathrm{~B} 0 \% 20 \% \mathrm{D} 0 \% \mathrm{BE} \% \mathrm{D} 1 \% 82 \% 202 \% 20 \% \mathrm{D} 0 \% \mathrm{~B} 0 \% \mathrm{D} 0 \% \mathrm{BF} \% \mathrm{D} 1 \% 80 \% \mathrm{D} 0 \% \mathrm{~B} 5 \% \mathrm{D} 0 \% \mathrm{~B}$ B\%D1\%8F\%202019\%20\%D0\%B3.\%20N\%2013\%D0\%90\%D0\%9F-3256|19/all:1. Accessed: 22.09.2019. (2019).

14. U.S. Code 47 Section 230 (Communications Decency Act). URL: https://www.law.cornell.edu/uscode/text/47/230. Accessed: 20.09.2019. (2019).

15. M. Zalnieriute, \& S. Milan, (2019). Internet architecture and human rights: Beyond the human rights gap. DOI: 10.1002/poi3.200. URL: https://onlinelibrary.wiley.com/doi/full/10.1002/poi3.200. Accessed: 22.09.2019. (2019). 